Clinical Sigms and symptoms.-He is much emaciated and very pale. The abdomen is slightly distended, At the inner half of the left costal margin a hard mass can be felt projecting downwards for a couple of inches. It is dull on light percussion. It is separated from the spleen, which is not enlarged, by a belt of resonance. It is continuous with the liver dullness. The liver does not extend below the costal margin.

\section{The Blood.}

The lencocyte chart of this case shows a very similar variation to that of the Hodgkin's disease. There is a marked daily rise and fall in the number of lencocytes. The variation on the average amounts to from 5,000 to 40.000 lencocytes per cubic millimetre of blood, an eightfold increase. The leucocytes reach their height about midday, and are lowest about midnight.

The total mononuclear percentage, however, unlike that of Case I (Hodgkin), remains at about normal level, and there seems to be a tendency for the mononuclear percentage to fall with the lencocyte rise. The temperature of this case lias so far remained normal, and during the period of observation the patient remained in bed.

\section{Further Observations on the Blood.}

Red Cells, 3,200,000 per cubic millimetre-They showed some poikilocytosis and basophilia. Occasional nucleated red cells and occasional microcytes were found. Haemoglobin 30 per cent.

Leucocytes.-The eosinophiles were slightly increased, sometimes as many as 8 per cent. Occasional myelocytes were seen, and there was an occasional increase of large mononuclear leucocytes. This case, in my opinion, also suggests the possibility of the presence of a protozoal parasite having a definite period of development. Again referring to Cabot (1904), I find that the leucocyte counts in cancer of any part of the body are very variable, from 3,000 per c.mm. to considerably over 100,000 per c.mm. of blood. Isolated counts, however, seem only to have been made, usually not more than once daily, so that I am led to believe that the variations recorded depender chiefly upon the fact that the blood was taken at different periods of the leucocytic cycle, the cycle having been missed owing to the infrequency of the counts. It is stated also that a digestion leucocytosis is seldom found in cancer of the stomach, so that the daily variation revealed in this case can hardly be attributed to a digestion lencocytosis, in which the leucocytes seldom increase to even twofold thcir number. It appears also that considerable variations in the character of leucocytes are found in cancer cases. It is stated by Cabot that 'Taylor, Osler and McCrae have found an increase of the large mononuclear leucocytes in some cases amounting to 26 per cent.

I think that these facts are also significant, as in malarial fever, in which there is a marked lencocytic cycle, marked variations also take place in the relative variety of lencocytes, and there is a marked increase in the number of large mononuclears.

Controls $A, B$, and $C$.- The lencocytes in these controls showed no abnormality in variety or numbers. Control A was a healthy female, aged 26 ; controls $\mathrm{B}$ and $\mathrm{C}$ werc healthy males, both 27 years of age. From this paper it will appear that repeated daily counting of leucocytes is likely to give a valuable method of diagnosis in variot s eliseases.

N.B.- None of the above cases, nor the controls, had any history of malarial fever, neither had they any septic complications.

Before concluding I would beg to thank Dr. Macalister and Dr. Lloyd Roberts for their kindness in giving me full scope in the examination of the blood of their patients.

Rerrerences.
1 Cabot (1904): Clinical Examination of Bloot, pp. 175, 434, 451, etc.

2 Ross and D. Thomson (1910): Some Enumerative Studies on Malarial Fever. Annals of Trop. Mell. and Parasit., vol. iv, 1). 267 Ross and D. Thomson (1910): A Case of Sleeping Sickness Studied by Precise Enumerative Method

4 Ross and D. Thomson (i9i1): A Case of Sleeping Sickness Studied by Precise Enumerative Methods : Further Observations. Prcc. Roy. Soc., $\mathrm{B}$, vol. Ixxxiii.

"D. Thomson (19i1) : (1) A Research into the Production, Life, and eath of Crescents, etc. (2) The Leucocytes in Malarial Fever, etc. "inals of Trop, Med. and Parasit., vol. v, No. 1, 1911.

(1911): Enumerative Studies in Grypanosoma yambiense and Trypanosoma rhodesiense in Rats

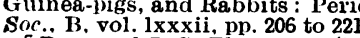

T Ross and J. G. Thompson (19i1): Experiments on the Treatment of Aninals Infected wit! Trypanosomes by Means of Atoxyl, Vaccines,
Cold, $x$ Rays, and Leucocytic Extract; Enumerative Methods Emploved. Proc. Roy. Soc., B, vol. 1xxxiii, 1). 227 to 234 Deut. Arch.f. Tilin. Med., vol, xvii. emssen's Handbuch d. Path, und Therap., vol. viii. Ber.

12. Amer. Journ. Med. Sciences, December, 1901 . the Numbers of Leucocytes and Blood Parasites per Cubic Millimetre. Aunals of Trop. Med. and Parasit., vol. v, No. 3.

\section{THE DANGERS OF SALINE INJECTIONS.}

\section{BY}

\section{EDWARD C. HORT, F.R.C.P.EDIN.,}

ANi

\section{W. J. PENFOLD, M.B., C.M.} (From the Lister Institute.)

Is recent years the practice of injecting hot solutions of saline into a vein, or under the skin, has greatly increased. The use of these injections in the prevention or treatment of operative shock, in the treatment of cholera or severe haemorrhage, or as a velircle for salvarsan or anaesthetics has fully proved their value. It appears, however, to be widely believed that the intravenous or subcutaneous injection of large quantities of saline is an entirely innocent procedure. On looking for trustworthy evidence in support of this belief, one is met with two striking facts: (1) The great variation in the quantities of liquid injected, together with absence of any serious attempt to graduate the volume of injection according to the body weight; (2) the wide variation in the absolute quantities of salt injected.

For some considerable time we have been studying the effects on animals of injection of saline solutions of various strengths, of distilled water, and of other liquids. Though our experiments werc undertaken for a very different purpose, the results may have some value in helping us to determine how far the administration to man of saline injections can be safely carried. We have, therefore, briefly summarized those points that bear on this question. We find that the injection of large quantities of normal or slightiy hypertonic saline solutions into a vein or under the skin is not nearly so innocuous a proceeding as is often sup. posed. The quantities injected were usually f'ar smaller than the quantities, relatively to body weight, that are frequently given in man. The undesirable effects that we encountercd include fever, rigors, subnormal temperatures, diarrhoea, intestinal haemorrhage, Cheyne Stokes breathing, convulsions, and sudden death. The last two we have only met with after injection of strongly liypertonic solutions, and, except in the case of young animals, only when the injection has been given rapidly. For all practical purposes of injection in man these acciclents may probably be neglected, though their occurrence in animals accentuates the need for caution in human injections. The other accidents mentioned occur: very frequently after injection into a vein or under the skin of normal or slightly hypertonic solutions. The grave sequel to large saline injections (in man) of pulmonary oedema has recently been noted in this Jourval. To this list of clinical drawbacks to saline injections in animals may be added the onset of glycosuria recorded by Martin Fischer and quoted by Bingel." ${ }^{2}$ We must also note the histological clianges observed by other workers's on this subject. Paum," for example, showed that intravenous injection of the dog with normal saline was followed by vacuolation of the liver cells. Allbrecht ${ }^{4}$ found that the red cells of animals were clamaged by large injections of normal saline; Rössle" obserred degenerative changes in the heart muscle and capillary walls of animals similarly injected, and Hössli ${ }^{6}$ found that saline injections caused in animals fatty changes in the heart muscle and kidneys. We cannot here discuss in detail all of these effects of saline injections, but one result-namely, feverwe may refer to, because it illustrates the points on which we wish to lay stress. It has long been known that injections of saline into a vein or under the skin in man or animals may set up ferer. In the last two years several papers have appeared on this subject in Germany, and in them it is often assumed that the fever which follows injection of saline is solely due to the salt injected and not to the water in which the salt is dissolved. In consequence, therefore, of the absence of proper controls, no constant 
attention has been paid to any relation between the extent of the fever produced by injection and the ratio of the volume of water injected to the weight of the animal receiving the injection. It is, therefore, frequently stated that the fever is proportionate in extent to the amount of salt injected. We find, however, that this is not the case, and that if certain precautions, which we shall later refer to, are taken with regard to the water used in making up the solutions no fever whatever follows the injection of saline solutions. We find, on the other hand, that con sideration of the ratio of the volume of liquid injected con taining the salt to the body weight is of the greatest importance. In other words, wc are able to show that some of the bad eflects nroduced by saline injections are more easily broncist abcat by injections of distilled watio as one of us has almady siown.? Whicther any benefit ensuing from saline injections is due to the salt, or to tho water, or to both, it is certain from car experiments tinat in animals injected with sufficicitly large volumes of saline, the influence for evil of the watsr injected cannot be ignored. The importance, therefore, of ensuring that the total volume injected does not cxceed a certain fraction of the body weight is manifest. The basis of this statement is the fact that in rabbits injection of volumes of saline below what we may call the critical point of safety produces no apparent ill effects, whilst the injection of quantities above this point does produce undesirable effects, and that in a very short time. What we have so far said relates mainly to single injections. When multiple njections are given, and still ruore when continuous injection is practised, unpleasant results ensue in proportionate degree. In attributing, however, the fever in our control experiments only to tho distilled water injected, there is a possibility of error.

In a recent paper by Wechselmann, ${ }^{8}$ attention is called to the dangers of intravenous injection of saline solutions of salvarsan. This observer believes that many of the unpleasant effects which he found to follow the injection of salvarsan were directly due to bacteria he found in the distilled water of the solutions he injected. He states that the rigors, fever, diarrhoea, vomiting, cyanosis, and headache which so many havc reported are due to the fact that the water used is not sterile, and that they can bo avoided by filtration of the water through hard filters and by heating in an autoclave. He bases his belief on the fact that the water he used when plated out gave a lixuriant growth of a Gram-staining spore-bearing bacillus. He admits, however, that slight fever still occurred in 19 per cent. of his cases even after filtration and heating of the water. If Wechselmann's finding of living bacteria in the water that he supposed to be sterile applies to all distilled water prepared and stored with the ordinary precautions observed in all laboratories, it is clearly a discovery of the greatest importance. It immediately concerns, in fact, every clinical or laboratory worker who believes that distilled water, collected and protected from infection with all the care incident to a surgical operation, is innocent of bacterial protein. Its interest to those who give injections of salvarsan in saline is evident. It equally affects all who inject solutions of saline in order to prevent or combat operative shock, or to those who treat cholera or other-diseases by the same method, as well as to those who administer anaesthetics by the intravenous route. It also seriously affects those engaged in studying experimental fever by the injection of solutions in which water supposed to be protein free is the solvent. And it is difficult to believe that it does not also affect the interpretation of serum reactions in the test tube, or in the living animal if the serums are diluted with water or saline. Finally, it cannot but affect the interpretation of the resnlts of using leucocytes or vaccines for purposes of diagnosis or treatment after repeated washing with solutions containing unsuspected organisms.

So far-reaching, in fact, are the possibilities involved by Wechselmann's observations that it becomes very necessary to determine if distilled water collected and kept under ordinary conditions of surgical cleanliness is or is not sterile. We have therefore gone very fully into this matter. Detailed observations will be found at the end of this paper. We find that if ordinary precautions are taken to prevent infection the number of organisms that can be cultivated from the distilled water we examined is quite insufficient to account for the fever. The possibility of multiplication of non-spore-bearing organisms in the body after injection is excluded by the custom of boiling all solutions of saline before injection, and the absence of spore-bearing organisms in the samples of water examined was shown by unsuccessful cultivation. We were also able to exclude the possibility of fever being caused by unaltered protein of living organisms, because the number of bacteria found on cultivation was in all cases too small. Control observations with virulent typhoid organisms showed that much larger numbers must be injected of these to produce fever. We found, moreover, that filtra. tion or centrifuging was ineffective in removing the feverproducing properties from any of the samples of water allowed to stand that we examined. On the other hand, we find that if water distilled in a suitable glass retort is at once injected into animals it does not produce ferer. On the contrary, freshly distilled water tends to produce on injection a marked fall of temperature. We are forced, therefore, to the conclusion that the results reported by Wechselmann must have been due to gross contamination of the watcr he employed. How, then, are we to explain our own results? We are driven to the suggestion that the fever which always follows the injection of suitable quantities of distilled water allowed to stand is caused by soluble products, perhaps of bacterial origin, and is not directly due to bacteria as such or to unaltered protein. From our innumerable experiments with distilled water injections, which will be published in duc course, we believe that Wechselmann's inability to prevent fever in 19 per cent. of his cases proves that he has not been able to get rid of the fever-producing properties that we find in ail! distilled water allowed to stand. In salvarsan therapy it must be remembered that the quantities of saline injected are relatively small. If, therefore, he had studied the ratio of volume of injection to body weight he would have found, as we have done, that the percentage of cases giving a febrile reaction after larger injections would, in spite of filtration and heating, have been considerably greater. To conclude, we think-

1. That saline injections as at present administered are by no means free from risk, especially when they are large.

2. That the cause of the toxicity of distilled water that is allowed to stand in sealed sterile vessels is not yet explained.

3. That neither centrifuging, filtration through cotton-wool or bacterial filters, nor boiling, is sufficient to prevent the fever that follows saline injections.

4. That distillation in a sterile Jena retort of all water used in the preparation of saline solutions, followed by inmediate injection, is at present the only reliable method of ensuring that no fever follows the injections.

It has been proposed that instead of injecting normal or slightly hypertonic solutions of saline, Ringer's solution may be a good substitute, on account of the inlibitory effect on fever that it is supposed to possess. Before, however, this can be accepted, fresh experiment must be undertaken with this solution, made up with water distilled in the manner suggested, and tested by injection for atoxicity.

\section{Experimental Data.}

1. Water obtained by distillation from a Jena glass retort, if injected at once, produced no fever. The amounts of water injected varied from one-five-thousandth to one-twenty-fifth of the body weight. This water, after standing for five hours, on plating gave four organisins per cubic centimetre. The total solids, kindly estimated by Dr. Young from $225.0 \mathrm{c.cm}$., were $1.7 \mathrm{mg}$.

2. A sample of the above water was autoclaved in a plugged Jena flask for ten minutes at $120^{\circ} \mathrm{C}$., and was allowed to stand at room temperature for forty-eight hours. On injection it produced marked fever. It was boiled before injection twice.

3. Distilled water as used for routine purposes was collected from a copper still into a closed tin-lined copper receiver, and immediately injected after boiling. It prodiced slight but constant rises of temperature. This water contained 160 organisms per cubic centimetre. The total solids from $225 \mathrm{c.cm}$. were $2 \mathrm{mg}$. 
4. Water from the same source allowed to stand for a few days or weeks in clean stoppered bottles constantly produced high fever after boiling. The amount of fever was always nearly proportionate to the volume injected. Several hundred observations were made. The total residue from 225 c.cm. of water that had stood for many weeks was $2.2 \mathrm{mg}$. Two different samples were plated out. (a) The water that had stood for two months gave 40 organisms per c.cm. (b) The water that stood for ten days gave 73,000 organisms per c.cm. The counts in all cases were made from agar plates grown for forty-eight hours at $37^{\circ} \mathrm{C}$. Counts made from agar plates at $22^{\circ} \mathrm{C}$. were taken on two occasions and gave very similar restulis. The water that contained 40 organisms per c.cm. gave a greater fever than that which gave 73,000 organisms. Both these waters were centrifugalized for thirty minutes in Dr. Martin's turbine centrifuge. Small quantities of the upper layers immediately below the surface invariably gave rise to high fever. The invisible deposit when injected in 0.50 c.cm. of water gave rise to no disturbance of temperature.

5. Distilled water that had been allowed to stand gave rise to fever after filtration either through a Doulton filter or through cotton-wool. Two filters were used. One was new, the other had been used several times. In both cases after filtration the water showed on analysis considerable quantities of calcium. Before filtration the ammonium oxalate test gave no reaction. The same results were obtained with a Berkefeld filter.

REFERENCES.

1 Grinbeum, A. S., and H., British MEdical Joers.le, November 11th, 1911. 2 Bingel, A., Arch., f. exip. Path. $u$. Pharm., 64, p. 1. 8 Raum, Arch. f. cxp. Path. u. Pharm., 1892. 4 Allbrecht, Lulur, Pch-Ostertags p. 1105. ${ }^{6}$ Hössli. Frankf. Zeitsch.f. Path., 2010, Bd. 4, p. 258. 7 Hort, E. C., Proc. of the Roy. Soc., B. vol. 1xxxii, 1910. \& Wechselmann, De'ut. med. Woch., April 27th, 1911, N. 17, p. 779.

\section{A REPOR'T OF SIX CASES OF ARSENICAL POISONING CAUSED BY FUMES FROM} A COKE STOVE.

BY

J. GEORGE TAYLOR, M.A., M.D.CANTAB., M.R.C.P.LOND.,

HONORARY PHYSICIAN, GENERAL INFIRMARY, CHESTER. AND

K. V. TRUBSHAW, M.B., B.S.Lovd., M.R.C.S., L.R.C.P.,

hoNoraRy SCRGEON, MOLD Cottage hospital.

There are many well-known ways by which arsenic can be slowly absorbed into the system, causing symptoms of poisoning, such as from wall-papers containing arsenic, but we do not remember having seen any record of arsenical poisoning being caused by fumes from a coal or coke stove. For this reason we think the following cases are of sufficient interest to be worth reporting.

On May 4th, 1911, one of us was called to see a girl working in a laundry who was suffering from vomiting and loss of power in her legs. As after a few days she did not improve, she was sent home, for there were no means of nursing her where she was working.

In the early part of June, 1911, two more girls were attacked with weakness in the legs and vomiting, followed in a few days by pain in the legs. When we together saw these two girls, on Jume 29th, 1911, one of them (Case II) was very ill indeed. Her face was cyanosed, and there was some puffiness of the eyelids. She seemed to be halfdazed, and lay in bed curled up. It was difficult to get an answer from her, and she gave the idea of being rather hysterical. She frequently vomited, but had no diarrhoea. Shs had diplopia, due to paresis of the external recti muscles; on making her look to either side, in addition to the eye not moving beyond the midale line, there was marked nystagmus of both eyes. The pupils were widely dilated, but reacted sluggishly to light. The legs were almost completely paralysed-they could not be raised from the bed or flexed at the knee by the patient, and her attempts to move them caused cramp. There was complete loss of sensation of touch below the linees, though sensations of heat and cold were normal. The calf muscles were exquisitely tender, the patient crying out on the slightest squeeze. There were no knee-jerks or plantar reflex, and, owing to loss of power in the tibialis anticus, the feet lay in bed with the toes pointing downwards. The pulse was slightly irregular. There were no changes in the skin. The other caso (Case III) was in practically the same condition, but less severe.

We both thought of arsenic as a possible cause, but the most thorough examination of ilse colouring on the walls and of the food failed to detect any anywherc. Wo searched the garden-a very large one, in which the workers were allowed to roam and pick leaves and flower's - foi poisonous plants, but failed to find any cause here.

'Two cr three days later another girl fell down while standing at a wash-tub, her legs sin!ply giving way under: her.

On July 3rd we again visited the laundry to make a further examination. Inquiry elicited the fact that all the cases at the time they were attacked either actually were, or had just been, working in the ironing room. We thoroughly examined this room; it was large and lofty, there was no crowding or lack of air space, and we could not find anything even suspicious here. Leading out of the ironing room up a few steps was the room where the irons were heated; this was a small room, $15 \mathrm{ft}$. long by $7 \mathrm{ft}$. broad, and about $8 \mathrm{ft}$. ligh. There was no window, and only one door leading to the ironing room. It was lighted by two very small sliylights, one of which was closed, and the other not half open. To open or close these lights some one had to climb on to the roof outside. There were two iron stoves in the room with the flues running straight up through the roof. The stoves were so placed that it was possible: to walk completely round each one, and each stovo had t? to stanil the irons, a worker bringing her cold iron in placing it on a shifs quite close to the stove to heat, and taking cut a liuti ons. The stoves, which were cracked in places, and the flues being red-hot, we thought it just posisible that the toxic agent might be carbonic oxide gas, for we found that colse, and not coal, was burnt in the stoves, as when coal was used the flues did not draw properly and the room became full of smoke; therefore, we thought that probably the air might be contaminated with CO gas both from the down-draught through the cracks, etc., and also possibly by the passage of the gas through the red-hot iron. We accordingly took sampees of the air in this room after having the stoves well stoked up, and the skylights and door closed for some time. We examined the blood of the two worst cases spectroscopically for carboxyhaemoglobin, but failed to detect it.

Mr. H. Lowe very kindly examined the air samples for us, and reported that there was no $\mathrm{CO}$ gas present in it, but a fair proportion of $\mathrm{SO}_{2}$ gas. Mr. W. F. Lowe, A.R.S.M., F.I.C., suggested that as $\mathrm{SO}_{2}$ was present in the air probably there was arsenic present in the coke used in the stoves, as " malt has frequontly been contaminated with arsenic by the use of coal or coke in the kilns instead of anthracite." He most kindly undertook to examine for arsenic the colke used in the stoves. His report was as follows: "The total amount of arsenic (calculated as $\left.\mathrm{As}_{2} \mathrm{O}_{3}\right)$ in the colke is 0.001 per cent., or $\frac{1}{14}$ grain per $1 \mathrm{~b}$. The fixed arsenic (as $\mathrm{As}_{2} \mathrm{O}_{3}$ ) - that is, the portion which remains in the ash when the coke is burnt-amounts to 0.0002 per cent. or 1 grain per lb., so that four-fiftlis of the total amount is volatile and passes off in fumes when the coke is burnt."

We have no doubt that the fumes from the coke escaping into the air of the stove-room were the cause of the poisoning in these cases and that the poisoning was arsenical, because we detected arsenic in the urine of the two worst cases admitted to Chester Infirmary, and the presence of this ar'senic was verified for us by $\mathbf{M r}$. W. F. Lowe. Since attention was drawn to the danger from the stoves no more cases have occurred. Coal only is used in the storcs, so that any leak can be at once recognizer by the smoke in the room, and a fresh stove has been installed in a bigger room.

CASE I.

F., aged 17 years. In February last this girl ran awar from the laundry and was out in the cold all night. Five days later she complained of pains in her legs. This continued until the end of April, when she began to vomit. There was " numbness 